Books, videos, CD-ROMs, DVDs and any

other relavent items submitted for a review

in the $B D J$ should be addressed to: Kate

Maynard, Assistant Editor, British Dental

Journal, NPG, 4-6 Crinan Street, London,

N1 9XW

\section{Clinical success in management of advanced periodontitis}

\author{
R. Detienville \\ UK: Quintessence \\ price $€ 46.00$, pp 120 \\ ISBN 2912550416
}

The aim of this book, published by Quintessence, is to advise and guide the GDP through the management of advanced periodontitis. This soft bound book has 120 pages with seven chapters, a glossary, a bibliography, and an index. It is well illustrated and attractively presented.

The author is an Assistant Professor at René Descartes University, Paris. Though the translation is adequate overall, several errors can be found in the text. For the most part these errors are merely irritating, though they could cause confusion for students starting their studies. My confidence in the text was left shaken on reading on page 9 that 'Advanced periodontitis is most often observed in younger patients'.

A certain level of knowledge is assumed. The author focuses on what he presumably believes is relevant to GDPs, excluding some underlying theory. This is likely to be of some relief to GDPs not wishing to relive their student days, but obviously limits its usefulness for exam study.

It is clearly stated that the book only considers chronic and aggressive forms of periodontitis. The first chapter discusses the criteria for, and prevalence of, advanced disease. Chapter two looks at pathogenesis including microbiological considerations. The third chapter reviews diagnosis. Included are the new classification system, signs and symptoms, microbiological analysis, and complexity factors. The fourth chapter discusses criteria for therapeutic success; effects of bacterial plaque control, scaling, root planing, surgical therapy; and the use of antibiotics and antiseptics. The fifth chapter discusses treatments: hygiene phase therapy, surgery, splinting, orthodontics, and implants. Chapter six looks at occlusal trauma, loss of posterior support, furcations, mobility, and high risk patients. The seventh chapter examines prognosis and long term outcome which includes the goals of periodontal management, limits to treatment, and maintenance.

Although aimed at GDPs, specialist referral would be appropriate for some of the cases illustrated. It is to some extent a hybrid - an atlas of periodontology and periodontics, but not a technical manual, with more supporting text than usual for an atlas and a sprinkling of references to the scientific literature. It is didactic in style, with little discussion of alternative treatment approaches. Those GDPs with a reluctance to treat advanced periodontitis, or whose knowledge is outdated, will probably find this text a pleasant read. Those dentists looking for a comprehensive reference book may wish to investigate other titles.

\section{OSCEs for dentistry}

A. Pye

K. F. M. Fan, J. Jones
UK: PasTest
price $£ 18.95$, pp 284
ISBN 190462751X

ISBN 190462751X

Objective Structured Clinical Examinations (OSCEs) are rapidly becoming the en vogue examination format in dentistry for testing both factual knowledge and clinical skills including ethics, communication and information delivery, as well as practical dental skills.

The preliminary pages of this book contain the preface, a useful introduction, a section on the duties of a dentist and a list of abbreviations. Although the latter is a useful inclusion, I for one would like to have seen a statement to the effect that abbreviations should not be used in routine clinical practice because these can be ambiguous. The main section of the book is populated with series of OSCE scenarios ordered into the main dental discipline groups. It is refreshing to see a specific set of scenarios on history taking and examination near the beginning and also a section on law and ethics towards the back of the book. However, it is unfortunate that orthodontics and child dental health are lumped together, limiting the range of scenarios that could be included. Specifically, there is no mention of questions about orthodontic appliance treatment, adult orthodontics or the multidisciplinary aspects of malocclusion. Nonetheless, the book is not intended to be a syllabus for all types of OSCE examinations, and those taking OSCE examinations will be able to compensate for these drawbacks to what is in general a good text. The book is illustrated with a number of colour pictures, but there is a significant bias to OMFS related illustrations, which is presumably a function of the authors' specialty interests.

The book is designed for undergraduate students and those taking the MFDS examination and is pitched at the right level. It will therefore be spotted on an increasingly frequent basis in dental schools. The book is not intended to be used for 'cover-to-cover' reading or alternatively for rote learning. Moreover, the book would be best for dipping into during spare clinical time or whilst travelling for example as I found I did whilst getting a feel for the book. Despite the minor criticisms detailed above, OSCEs for dentistry is a welcome addition to the growing stable of books covering the various examination formats and examination techniques in dentistry. I would recommend it as a 'must have' text for undergraduate students and those sitting the surgical royal colleges' MFDS examinations.

G. T. McIntyre

Netter's head and neck anatomy for dentistry

\section{N.S. Norton \\ UK: Elsevier \\ price €26.99, pp 610 \\ ISBN 1929007884}

This book consists of 21 chapters over 610 pages and is packed with information 

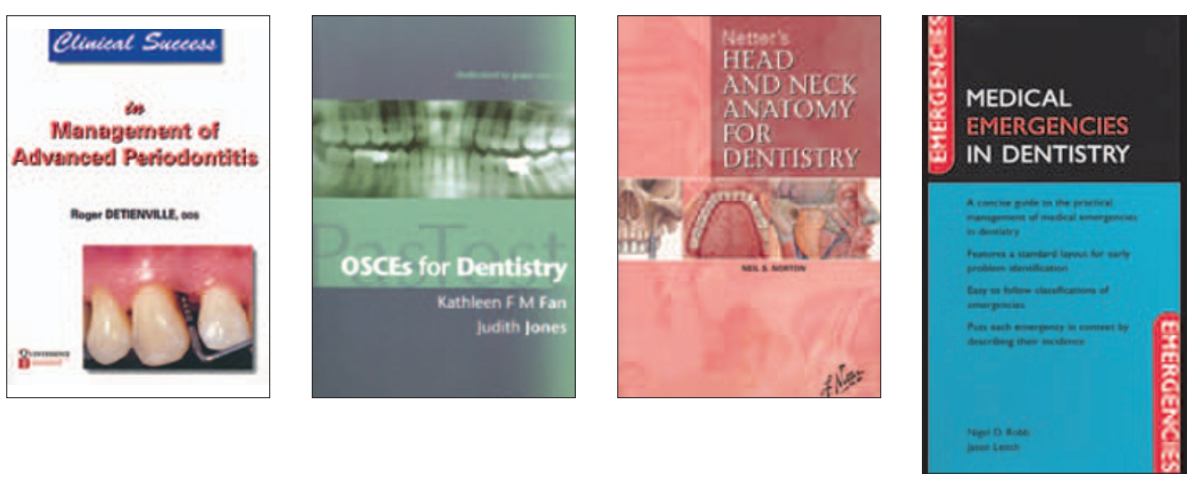

essential for any student wishing to qualify in the basic undergraduate degree of dentistry.

It has clear details in each chapter with a section which begins the consideration of clinical relevance at the end of each chapter. Each chapter is logically laid out and provides clear detail of all aspects of head and neck anatomy. It is very gratifying that the autonomic nervous system has been detailed in its own chapter. From a student who spent a ridiculous number of hours turning the pages of traditional textbooks piecing together one of the major controlling mechanisms in the human body, it is pleasing to see the precise detail at last placed together for all to see. The final chapter (prior to the appendix detailing lymphatic drainage) provides a robust description of anatomy with respect to local anaesthesia. The labelling in all chapters is clear and whilst there is an absence of extensive turgid narrative, the information is extensive and very well laid out.

The diagrams are clear and precise; my only disappointment is that the book is not supplied with a CD with all the images available for lectures and teaching. This book has to be recommended for all those wishing to establish the appropriate level of knowledge for the contemporary practice of dentistry and for those wishing to refresh their knowledge.

No dental library should be without this book, let alone a dental practice.

F. McDonald

\section{Medical emergencies in dentistry}

\section{N. D. Robb, J. Leitch \\ UK: Oxford University Press \\ price $€ 19.95$, pp 158 \\ ISBN 9780198529316}

This slim, pocket sized book is yet another valuable addition to the range of books by Oxford University Press. It comprises around 150 pages and details medical emergencies in dentistry in a well written, concise manner. The authors are Nigel D. Robb, Senior Lecturer in Sedation in Relation to Dentistry, and Jason Leitch, Clinical Lecturer in Oral Surgery, both from Glasgow Dental Hospital and School. There are 10 chapters which include an introduction, risk assessment, basic, immediate and advanced life support, circulatory, central nervous system, endocrine, respiratory, drug-related, and cardiovascular system-related emergencies. Each chapter begins with a brief introduction explaining the relevance of the topic and gives bullet points under the headings of diagnosis, exclusions, immediate action, follow-up action, delayed management and risk factors. Each point is then explained in more detail. Headings are well highlighted and simple and black and white illustrations are used where practical demonstrations are necessary to aid understanding.

This book is a useful source of information and is extremely easy to follow. Reporting of incidences allows the reader to appreciate which emergencies they are more likely to encounter. Current protocols are described with references made to literature and guidelines to consolidate the material. General dental practitioners will find this a very helpful book in highlighting their role in medical emergencies whilst staying within their capabilities. They may also find it a useful teaching tool within the practice for the dental team. This book could also be used by undergraduates as an initial source of information and its small size allows it to be easily carried for reference.

Medical emergencies can occur at any time in a dental setting, therefore being prepared for such an event is of utmost importance. This book cannot be regarded as a replacement for training courses, which are essential to stay up to date with changing protocols, but it is a very useful adjunct in understanding and managing medical emergencies in dentistry. 